\title{
Analysing the spatial patterns of erosion scars using point process theory at the coastal chalk cliff of Mesnil-Val, Normandy, northern France
}

\author{
J. Rohmer and T. Dewez \\ BRGM, 3 av. C. Guillemin, B.P. 36009, 45060 Orléans Cédex 2, France \\ Correspondence to: J. Rohmer (j.rohmer@brgm.fr) \\ Received: 25 August 2014 - Published in Nat. Hazards Earth Syst. Sci. Discuss.: 24 September 2014 \\ Revised: 16 January 2015 - Accepted: 19 January 2015 - Published: 27 February 2015
}

\begin{abstract}
Over the last decade, many cliff erosion studies have focused on frequency-size statistics using inventories of sea cliff retreat sizes. By comparison, only a few paid attention to quantifying the spatial and temporal organisation of erosion scars over a cliff face. Yet, this spatial organisation carries essential information about the external processes and the environmental conditions that promote or initiate sea-cliff instabilities. In this article, we use summary statistics of spatial point process theory as a tool to examine the spatial and temporal pattern of a rockfall inventory recorded with repeated terrestrial laser scanning surveys at the chalk coastal cliff site of Mesnil-Val (Normandy, France). Results show that: (1) the spatial density of erosion scars is specifically conditioned alongshore by the distance to an engineered concrete groyne, with an exponential-like decreasing trend, and vertically focused both at wave breaker height and on strong lithological contrasts; (2) small erosion scars $\left(10^{-3}\right.$ to $\left.10^{-2} \mathrm{~m}^{3}\right)$ aggregate in clusters within a radius of 5 to $10 \mathrm{~m}$, which suggests some sort of attraction or focused causative process, and disperse above this critical distance; (3) on the contrary, larger erosion scars $\left(10^{-2}\right.$ to $\left.10^{1} \mathrm{~m}^{3}\right)$ tend to disperse above a radius of 1 to $5 \mathrm{~m}$, possibly due to the spreading of successive failures across the cliff face; (4) large scars significantly occur albeit moderately, where previous large rockfalls have occurred during preceding winter; (5) this temporal trend is not apparent for small events. In conclusion, this study shows, with a worked example, how spatial point process summary statistics are a tool to test and quantify the significance of geomorphological observation organisation.
\end{abstract}

\section{Introduction}

Though shoreline is mostly rocky worldwide (80\% according to Emery and Kuhn, 1982), our understanding of the physical processes underlying its dynamics remains limited. Therefore rocky coasts have seen a growing interest from the scientific community over the last few decades, and more specifically in the context of shoreline response to climate change (see a recent review by Naylor et al., 2010). Several studies (e.g. Sunamura, 1992; Bird, 2000) have shown that cliffs recess under an intermittent and discontinuous series of rock collapses.

A possible approach to predict the occurrence of sea-cliff instabilities and the induced cliff retreat is to rely on statistical and probabilistic methods. These examine frequencysize statistics using inventories of sea-cliff retreat sizes, such as scar surface or retreat volume associated with sea-cliff retreat (Dong and Guzzetti, 2005; Marques, 2008; Brunetti et al., 2009; Lim et al., 2010; Young et al., 2011; Dewez et al., 2013). Such studies have been made possible thanks to the advances in landslide/rockfall inventories (see the recent review by Guzzetti et al., 2012) and more specifically through the use of terrestrial laser scanner (TLS). Surveys based on repeated TLS have demonstrated their capabilities in building dense digital surface models (DSM) of cliff faces (among many others see Rosser et al., 2005, 2007; Lim et al., 2010; Dewez et al., 2007, 2013), based on which erosion scar inventories can be collated with high accuracy not only in terms of sizes, but also of spatial locations over the cliff face.

Yet, only a few studies have addressed the statistical characteristics of this spatial distribution (e.g. spatial density, spa- 
tial homogeneity, isotropy, etc.). These can be of great interest, because these spatial signals carry information about the external processes and the environmental conditions that promote or initiate sea-cliff instabilities. Recent examples of spatio-temporal failure analysis are provided by Rosser et al. (2007), Stock et al. (2012), and Royán et al. (2013). Extracting and drawing robust statistical inferences from spatial patterns have been proposed for numerous natural objects as diverse as plants (Wiegand et al., 2006), forest fires (Hering et al., 2009), earthquakes (Schoenberg, 2003), landslides (Tonini et al., 2014) and very recently rockfalls in a mountainous context (Tonini and Abellan, 2014). Through the abstraction of these objects as points (for instance the hypocentres of earthquakes), the analysis of spatial pattern relies on the strong statistical background provided by the "point process theory" (see Diggle, 2003 and references therein).

The primary objective of the present article is to investigate the organisation of erosion scars in space at different epochs. Scars are viewed as points corresponding to their geometrical centroids provided by TLS with high accuracy. In this view, we use the summary statistics of point process theory transferring the approach of the studies cited above to a new context. We use an inventory of more than 8500 sea cliff failures collated from repeated TLS surveys (6 measurement epochs over 2.5 years) along a coastal chalk cliff in Normandy, NW France (see details in Dewez et al., 2013). To better appreciate the nature of the geological object at the core of the study, the reader can refer to Figs. $1 \mathrm{~b}$ and 2. Two types of erosion scars are considered depending on their volumes: either small or large erosion scars (definition discussed in Sect. 2). For both scar types, the following exploratory questions are addressed:

- Question 1 "spatial distribution": is the erosion scar density even over the cliff face or is it focused somewhere? Put another way, do the underlying physical processes and disturbances act evenly over space (i.e. are they spatially homogeneous?) or at specific locations (i.e. spatially heterogeneous)? Does this distribution differ for small or large scars?

- Question 2 "spatial dependence": considering both sizes of erosion scars separately (small or large), do the events occur independently of each other or do they cluster, suggesting some forms of interactions?

- Question 3 "temporal dependence": do events locate where past events have already occurred, i.e. in regions, which have already experienced erosion processes? Does this dependence differ for small or large scars?

The present paper is organised as follows. In Sect. 2, we describe the study site at Mesnil-Val and the inventory of sea-cliff erosion scars. We discuss the validity of assuming a point-like behaviour. In Sect. 3, we briefly introduce the basic theoretical concepts of point process theory and their summary statistics. In Sect. 4, the research questions are then applied to the Mesnil-Val inventory. Finally, the statistical results are discussed from a natural hazard assessment perspective.

\section{Data}

\subsection{Mesnil-Val chalk cliffs context}

Chalk coastlines are found on both side of the English Channel with ca. $150 \mathrm{~km}$ of chalk cliffs along the French coast and ca. $40 \mathrm{~km}$ along the British coast (Duperret et al., 2004). Mesnil-Val is located between Criel-sur-Mer and Le Tréport in Normandy (northern France, see inner panel of Fig. 1a for location). Mesnil-Val cliffs are entirely made of Upper Cretaceous chalk dated to Upper Turonian to Lower Coniacian and known as Lewes Nodular Chalk (Mortimore et al., 2001). This lithological facies denomination relates to specific chalk geotechnical properties described in (Mortimore et al., 2001). The study site is a $\sim 750 \mathrm{~m}$-long (Fig. 1b) and rises from $20 \mathrm{~m}$ above IGN (French national geographic institute) datum, in the SW, at the level of the suspended dry valley of Mesnil-Val to reach $80 \mathrm{~m}$ toward Le Tréport. The cliff profile is mostly vertical with undercaving at the foot demonstrating that the base of the cliff retreats faster than the top (Dewez et al., 2007, 2013). In this region, average decadal cliff retreat rate computed from ortho-photos clifftop mapping reached $15 \mathrm{~cm} \mathrm{yr}^{-1}$ between 1966 and 1995 (Costa et al., 2004). This rate is coherent with the average millennial cliff retreat rate of $11-13 \mathrm{~cm} \mathrm{yr}^{-1}$ obtained from cosmogenic isotope Beryllium-10 concentration found in platform in situ flint stones (Regard et al., 2012).

The cliff face was surveyed with a TLS at six epochs, bracketing winter and summer seasons namely December 2005, March 2006, August 2006, March 2007, September 2007 and April 2008. The survey spans a period of 855 days (about 2.5 years) with a time interval between successive acquisitions of about 5-6 months. The length of the surveyed cliff section was chosen to be sufficiently long to capture a maximum of erosion events while remaining practical to survey on a regular basis given the time constraint imposed by tides. The TLS used is a Riegl time-of-flight laser scanner designed to capture 3-D topographic points from a groundbased station. Survey details have been discussed in Dewez et al. (2013).

\subsection{Erosion scar inventory}

Raw laser point clouds were gridded into $5 \times 5 \mathrm{~cm}$ raster DSM and differenced epoch-to-epoch to identify statistically significant changes in the cliff topography, allowing for recording an inventory of more than 8500 erosion scars together with locations, epoch of occurrence and volumes (Dewez et al., 2013). In this study, each topographic change 

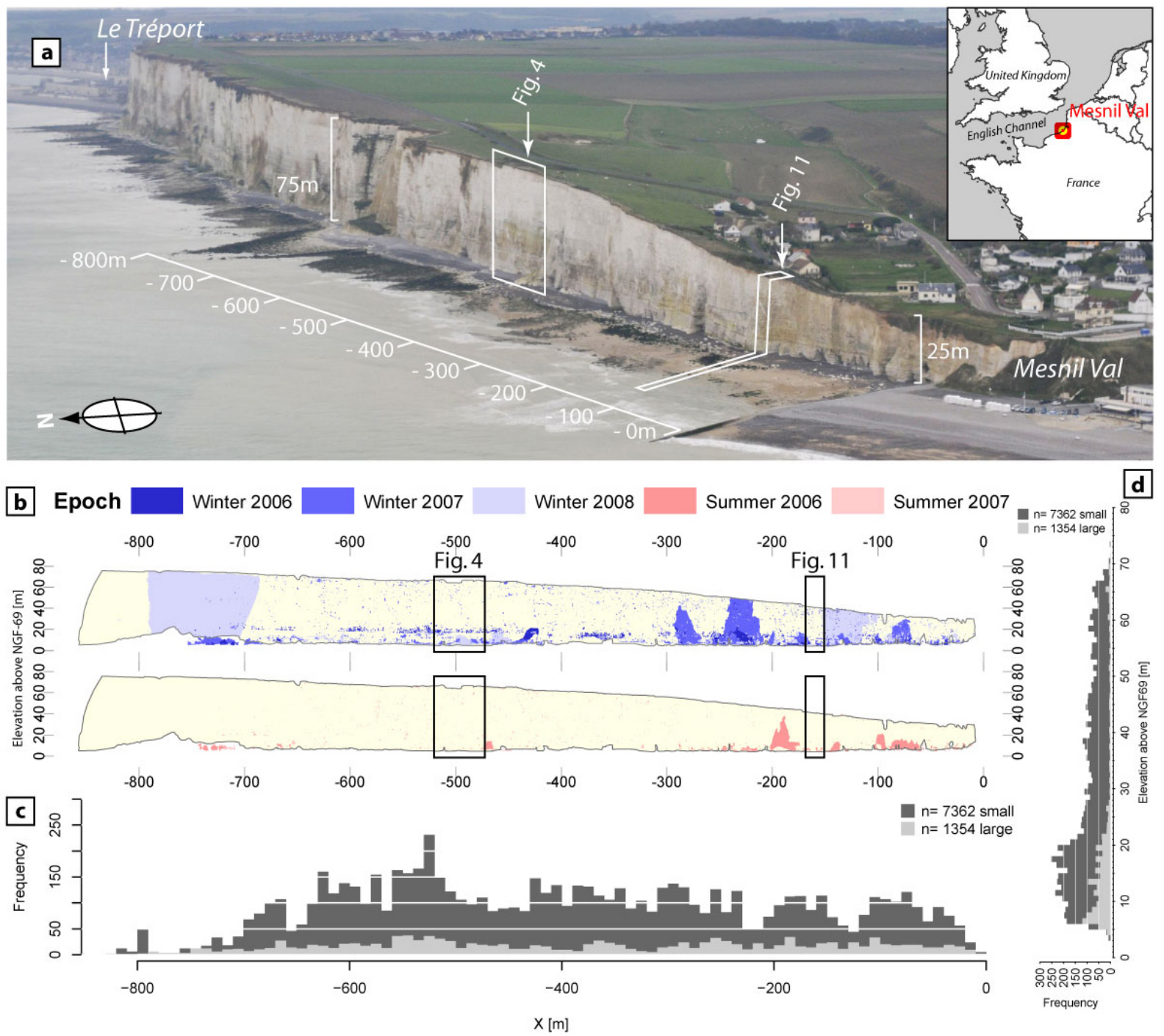

Figure 1. (a) Aerial view of the Mesnil-Val coastal rock cliff site (NW France, location indicated in the inner panel), photo T. Dewez, 5 October 2010; (b) distribution of erosion scars over the cliff surface considering the measurement epochs in winter (top) and in summer (bottom); frequency of small and large scars alongshore (c) and along the cliff height (d). The histograms are constructed by considering the centroids of the scars (see also Fig. 2). Location of Figs. 4 and 11 are indicated.

between two successive TLS surveys is assumed to be related to a single erosion event. This assumption depends on the six-monthly temporal resolution on our survey, which is further discussed in Sect. 5. Single point position precision at two standard deviations is $1.5 \mathrm{~cm}$. Further details on the monitoring protocol, data processing and feature extraction can be found in (Dewez et al., 2013).

This inventory ranges over 3 orders of magnitude in length $\left(10^{-2}\right.$ to $10^{1} \mathrm{~m}$ either in width, height or thickness), 6 orders of magnitude of area $\left(10^{-2}\right.$ to $\left.10^{4} \mathrm{~m}^{2}\right)$ and 8 orders of magnitude of volume $\left(10^{-4}\right.$ to $\left.10^{4} \mathrm{~m}^{3}\right)$. Inventory completeness was assessed based on the approach developed in seismology. Completeness was then demonstrated over the volumes' range from $10^{-3}$ to $10^{2} \mathrm{~m}^{3}$. In the following, we focus on volume measurements as a proxy for the magnitude of the erosion event. Table 1 summarises the seasonal inventory variations while Fig. 2 provides the spatial distribution of: (a) all scars at different measurement epochs; the centroids of the (b) large and (c) small volumes.

Our observations show that erosion scars preferentially occur during winters and towards the base of the cliff (see bluecoloured markers at the base of cliff in Fig. $2 b$ and c). This clearly relates to sea actions through a combination of interacting processes (Brossard and Duperret, 2004; Wolters and Müller, 2008 and references therein). At Mesnil-Val, the cliff foot suffers from waves breaking directly on the cliff surface at nearly every spring and neap high tide. Breaking waves play as pistons loaded with an explosive mixture of 
Table 1. Inventories of erosion scars collated at different epochs of measurement: "small" events correspond to a volume range [10 ${ }^{-3}$ to $10^{-2} \mathrm{~m}^{3}$ ], "large" events correspond to a volume range $\left[10^{-2}\right.$ to $\left.10^{1} \mathrm{~m}^{3}\right]$, "very large" events have volumes larger than $10^{1} \mathrm{~m}^{3}$. The total number of events corresponds to all events with volume above $10^{-3} \mathrm{~m}^{3}$.

\begin{tabular}{|c|c|c|c|c|c|}
\hline $\begin{array}{l}\text { Epoch of } \\
\text { measurements }\end{array}$ & Date & $\begin{array}{c}\text { Total number } \\
\text { of events* }\end{array}$ & $\begin{array}{l}\text { Number of } \\
\text { "small" events }\end{array}$ & $\begin{array}{l}\text { Number of } \\
\text { "large" events }\end{array}$ & $\begin{array}{c}\text { Number of } \\
\text { "very large" events }\end{array}$ \\
\hline Winter 2006 & December 2005-March 2006 & 1360 & $\begin{array}{c}1060 \\
(77.9 \%)\end{array}$ & $\begin{array}{c}278 \\
(20.4 \%)\end{array}$ & $\begin{array}{c}22 \\
(1.7 \%)\end{array}$ \\
\hline Summer 2006 & March-August 2006 & 704 & $\begin{array}{c}578 \\
(82.1 \%)\end{array}$ & $\begin{array}{c}117 \\
(16.6 \%)\end{array}$ & $\begin{array}{c}9 \\
(1.3 \%)\end{array}$ \\
\hline Winter 2007 & August 2006-March 2007 & 2072 & $\begin{array}{c}1760 \\
(84.9 \%)\end{array}$ & $\begin{array}{c}303 \\
(14.6 \%)\end{array}$ & $\begin{array}{c}9 \\
(0.5 \%)\end{array}$ \\
\hline Summer 2007 & March-September 2007 & 469 & $\begin{array}{c}403 \\
(86.0 \%)\end{array}$ & $\begin{array}{c}66 \\
(14.0 \%)\end{array}$ & $\begin{array}{c}0 \\
(0.0 \%)\end{array}$ \\
\hline Winter 2008 & September 2007-April 2008 & 1937 & $\begin{array}{c}1520 \\
(78.4 \%)\end{array}$ & $\begin{array}{c}405 \\
(20.9 \%)\end{array}$ & $\begin{array}{c}12 \\
(0.7 \%)\end{array}$ \\
\hline
\end{tabular}

* volume $>10^{-3} \mathrm{~m}^{3}$

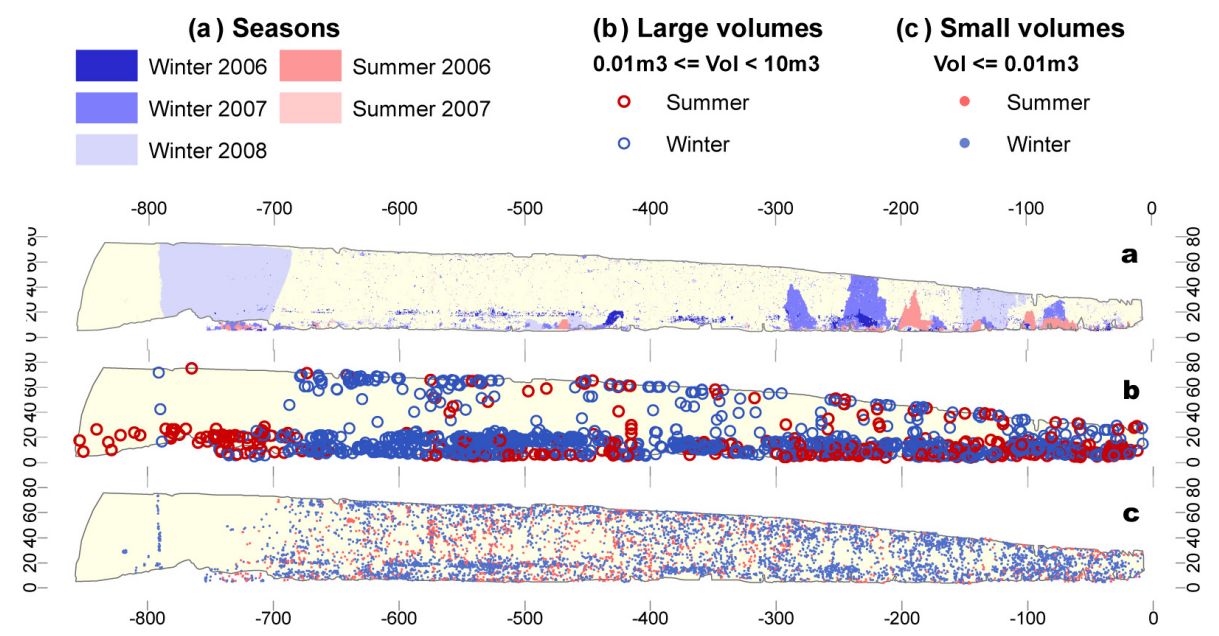

Figure 2. Spatial distribution considering the large and small events for all seasons (winters in blue and summers in red): (a) scars whatever their size; (b) centroids of the large volumes; (c) centroids of the small volumes.

water and air bubbles suddenly pressurising the chalk surface. All the weaker defects contained in the chalk, like material heterogeneities and joints/bedding surfaces, focus the energy on their edges and progressively open and deepen the joints. This ends up dislodging strata-bounded metre-size blocks and creates deep, narrow, caves at the base of the cliff (see e.g. Brossard and Duperret, 2004, Fig. 3b in a similar context; see also caves at the base of the cliff on Fig. 1a). The several-metres-deep caves leave entire cliff faces hanging in thin air. With gravity and weakening by fatigue, water-table loading and possibly wetting and drying cycles with salty water, the overhanging chalk fails massively in single thousands of cubic metre events (Dewez et al., 2013).

The scar inventory also contains a different type of scars. Above 15-20 m elevation, a clay-rich marl, known as Lewes Marl (Mortimore et al., 2001) keeps a perched water table. At winter-time, during frost events, the water-saturated $\sim 3-$
$5 \mathrm{~m}$ chalk bed suffers from frost shattering. Frost spalling leaves coalescent, centimetre-thick, scars in this specific stratigraphic bed (see Fig. 2b around the abscissa $-500 \mathrm{~m}$ where it is well visible for winter 2006). Elsewhere, the chalk is better drained and this frost-erosion effect is less noticeable. Beyond this hydrological barrier, the Lewes Marl also plays as a mechanical decoupling layer for the lower cliff. It is often the top of detached blocks.

These field observations and inferences are now explored with statistical support.

\subsection{Assumption for point abstraction}

A critical aspect of point process theory application is whether the concept of a point itself is applicable. Erosion scars are indeed polygons, not points. We will, however, assume that polygons can cautiously be represented by their 

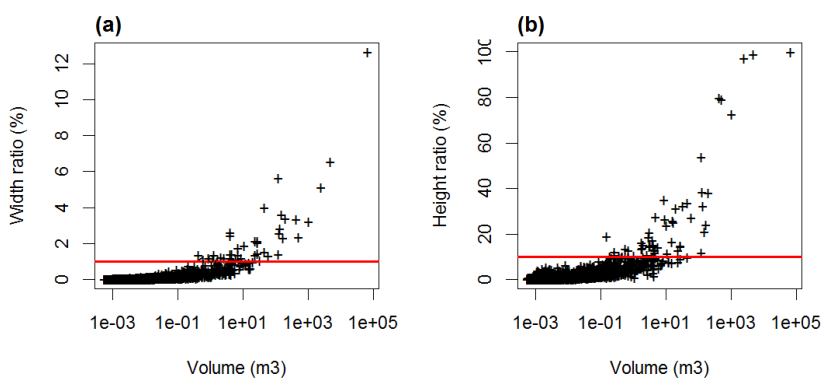

Figure 3. (a) Relationship between the ratio of erosion scars' width to the overall cliff length $(\%)$ and the volume $\left(\mathrm{m}^{3}\right)$.The red horizontal line outlines the threshold at $1 \%$; (b) relationship between the ratio of erosion scars' height to the overall cliff height $(\%)$ and the volume $\left(\mathrm{m}^{3}\right)$. The red horizontal line outlines the threshold at $10 \%$.

geometrical centroid point so long as the scar dimensions relative to the cliff dimensions are negligible. Using Fig. 3a and $\mathrm{b}$, the threshold for selecting acceptable point-like scars from the complete inventory is estimated. The ratio between scar width and cliff width, as well as scar height with cliff height is plotted versus scar volume. Width-wise, scars need to be smaller than $1 \%$ of the cliff width $(750 \mathrm{~m})$. Height-wise, they need be smaller than $10 \%$ of the cliff height with computed height ratios accounting for lateral cliff height variations (see Fig. 1). Resulting point-like scar volumes are comprised between $10^{-3}$ and $10^{1} \mathrm{~m}^{3}$ and contain $\sim 76 \%$ of the overall scar inventory.

As mentioned above, the selected scars were split into two groups: "small" and "large" events with a threshold set at $10^{-2} \mathrm{~m}^{3}$. Small events make up $\sim 80 \%$ of the $\left[10^{-3}\right.$ to $10^{1} \mathrm{~m}^{3}$ ] sample (Table 1). Figure $1 \mathrm{c}$ and d provide the frequency for both types of scar events respectively alongshore and along the cliff height (the histograms are constructed using the scars' centroids and not the entire polygon extent).

For rockfall scars larger than those sampled, their imprint is no longer negligible with respect to the cliff dimensions and cannot cautiously be abstracted to point-like features. In this case, more evolved spatial statistics do account for the shape of the scars, using for instance the gridand simulation-based approach developed by Wiegand et al. (2006). This however goes beyond the scope of this paper and will not be discussed here.

\subsection{Qualitative analysis}

As an illustration, we show in Fig. 4 a zoom on the cliff (see location in Fig. 1b) with point-like scars represented by their centroids. A few qualitative observations can be made regarding our research questions:

- Question 1 "spatial distribution": small events seem to spread almost uniformly over the entire cliff (marked by black squares in Fig. 4), whereas larger events primarily concentrate towards the cliff foot with a tendency to align at an elevation of $15-20 \mathrm{~m}$ (marked by elongated black rectangles in Fig. 4). This feature can also be seen over the entire cliff surface on Fig. 2.

- Question 2 "spatial dependence": depending on the epoch of measurement, there are clear occurrences of clustered events (marked by black circles in Fig. 4).

- Question 3 "temporal dependence": some events seem to recur on past scars (see in particular around $(-425 \mathrm{~m}$; $60 \mathrm{~m})$ - marked by an arrow in Fig. 4 at the different epochs).

Figure 4 serves to illustrate the spatial features observable on the entire cliff face, even though the quantitative analysis was conducted over the entire cliff surface (Sect. 4). In the following, we will show how exploratory tools of spatial point process theory can quantify the statistical significance of these qualitative observations.

\section{Point process theory}

A spatial point process is a type of random process, where a set of points defined by their geographical coordinates $(x$; $y$ ) is generated following pre- defined stochastic laws in a given delimited spatial domain of finite area at a given instant in time (Diggle, 2003). Applied to erosion scars, the spatial domain is the sea-cliff face boundary (Fig. 1b), individuals are erosion scars represented by their geometrical centroid whose locations are given by their Cartesian coordinates. The spatial structure of a point process can be described through different summary statistics, which are detailed below. Technically, we conducted the explanatory analysis using the "spatstat" package (Baddeley and Turner, 2005) of the R software (R Development Core Team, 2014), which is also that used by Tonini and Abellan (2014) to analyse rockfalls in a mountainous context.

\subsection{Spatial intensity}

Let us define the spatial intensity as the mean number $N$ of points per unit area and can be understood as the mean of a given sample of observations, i.e. it is a spatial average. Consider a spatial domain, the intensity $\lambda(a)$ (also named density) at location $a=(x, y)$ is defined as follows:

$\lambda(a)=\lim _{\mathrm{d} S \rightarrow 0}\left(\frac{E(N(\mathrm{~d} S))}{\mathrm{d} S}\right)$,

where $\mathrm{d} S$ is an infinitesimal (elementary) area around the point $a ; E$ is the expected value operator. The probability to find a point driven by a given point process in a disc with centre's coordinate $a$ and infinitesimal area $\mathrm{d} S$ is then $\lambda(a) \mathrm{d} S$.

The simplest spatial point process corresponds to the homogeneous Poisson process, which describes complete spatial randomness, denoted CSR. The characteristics of such 

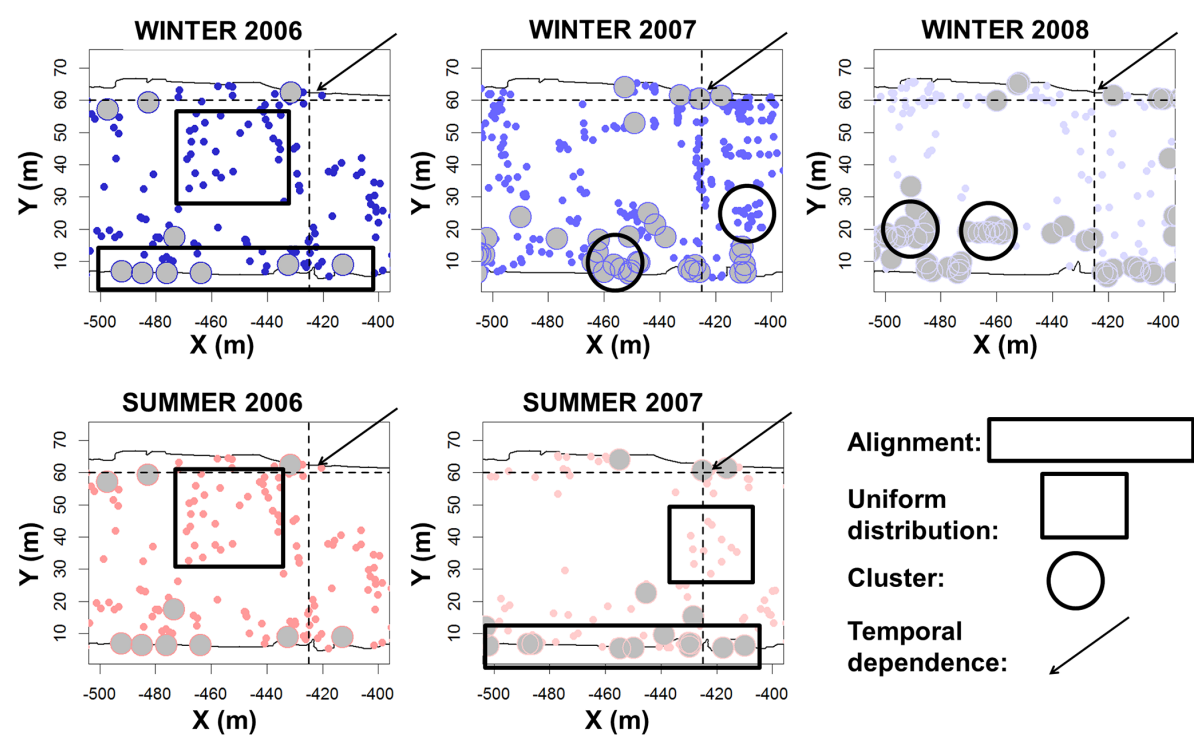

Figure 4. Zoom on the cliff (located between $x=-500 \mathrm{~m}$ and $x=-400 \mathrm{~m}$, see Fig. 1b). The erosion scars are outlined by different colours, each of them corresponding to a different epoch of measurement (see Table 1 for more details). Small erosion scars (volume ranging from $10^{-3}$ to $10^{-2} \mathrm{~m}^{3}$ ) are outlined by plain dots, whereas large scars (volume ranging from $10^{-2}$ to $10^{1} \mathrm{~m}^{3}$ ) are outlined by grey-coloured dots. Black-coloured marker outlines regions, where observations might suggest specific spatial patterns (see text for details).

a process are homogeneity and independency, so that points locate independently of each other in a given region following a uniform distribution: spatial intensity $\lambda$ is thus constant over space. Hence, points following CSR are completely random and in this sense, their occurrence can be said to be "unpredictable" (over space).

\subsection{Second-order statistics}

Second-order statistics of point process theory can be used to address the question underlying the spatial interaction between erosion scars, i.e. whether the relative positions of pairs of points depend on each other. To describe the smallscale spatial correlation structure of the point pattern, one commonly-used summary measure is the Ripley's $K$ function (Ripley, 1976) defined as follows:

$K(r)=\lambda^{-1} E\left[n_{\mathrm{e}}\right]$,

where $\lambda$, defined by Eq. (1), is constant under CSR conditions and $n_{\mathrm{e}}$ is the number of extra events within distance $r$ of a randomly chosen event. Equation (2) corresponds to the expected number of points in a circle of radius $r$ centred on an arbitrary location (which is not counted).

In practice, it is often easier to use a variant of this measure corresponding to the $L$ function (Besag, 1977) defined as:

$L(r)=\sqrt{K(r) / \pi}$

Its variance is approximately constant under CSR. The $K$ and $L$ functions can be used to identify spatial patterns characterising different forms of interaction between points:
- If $L(r)-r=0$, then points are distributed independently and homogenously, hence corresponding to CSR;

- if $L(r)-r>0$. then pairs of points are more abundant than the constant density $\lambda$ up to distance $r$. This means that the points interact and attract each other. This results in a spatial pattern characterised by local clusters (aggregation) of points;

- if $L(r)-r<0$, then pairs of points are less abundant than $\lambda$ up to distance $r$ i.e. the points repulse each other and disperse. Since the spatial domain is limited, this repulsion results in a regular spatial pattern.

Estimating the $K$ (or $L$ ) functions faces two issues. The first problem referred to as "edge effect", is linked to the points lying close to the domain boundaries. Since the estimation of the functions relies on counting the points within an observation window, a part of this window will fall outside the domain in the vicinity of the borders. This will result in the under-estimation of the summary functions. Several methods for edge correction exist (e.g. Haase, 1995) and the more usual one weights inter-point distances proportionally to the size of the distance between points (Ripley, 1988).

The second problem relates to the assumption of spatial homogeneity (i.e. of constant $\lambda$ ), which may not be valid, because the underlying physical processes usually vary within the considered spatial domain. The expressions of the second-order summary statistics should be modified by including the dependence on the locations $a=(x, y)$ in the expression of $\lambda$. For instance, this can be estimated by means of a "leave-one-out" kernel smoother as proposed by Badde- 
ley et al. (2000). A generic expression for the estimator of the $K$ function in the inhomogeneous case and taking into account edge correction is:

$K_{\text {inhom }}(r)=\frac{1}{D} \sum_{i} \sum_{i \neq j} \frac{I\left(\left\|a_{i}-a_{j}\right\| \leq r\right)}{\lambda\left(a_{i}\right) \lambda\left(a_{j}\right)} e\left(a_{i} ; a_{j} ; r\right)$

where $r$ is the distance, $e\left(a_{i} ; a_{j} ; r\right)$ corresponds to the edgecorrection weight, $I$ is the indicator function and $D$ corresponds to the sum of all terms $1 / \lambda\left(a_{i}\right)$.

Usually, the points can be assigned a property, which can be either qualitative (such as the lithology, epoch when they occurred, scar size category, etc.) or quantitative (such as erosion scar dimensions). To integrate point properties, called "marks" in the analysis, the $K$ function can be generalised with the cross-type $K_{i j}$ function defined in the homogeneous case (e.g. Wiegand and Moloney, 2004):

$K_{i j}(r)=\lambda_{j}^{-1} E\left[n_{j i}\right]$,

where $\lambda_{j}$ corresponds to the spatial density of the type $j$ point-like object, and $n_{j i}$ is the number of type $j$ events within the distance $r$ of a randomly chosen type $i$ event. Attempts to answer question 1 led us use the inhomogeneous version of the cross-type function (see Sect. 4.1).

\section{Application}

In this section, the tools of spatial point process are applied to Mesnil-Val to answer the three research questions (Sect. 4.14.3). Results are first discussed in statistical terms below and are then examined from a geomorphological and natural hazard standpoint in Sect. 5.

\subsection{Spatial distribution}

At Mesnil-Val, we investigated whether the spatial intensity $\lambda$ varies alongshore ( $x$ coordinate) or/and along the cliff height ( $y$ coordinate) or whether it remains constant. From a geomorphological point of view, constant density would imply that the physical processes causing cliff erosion act evenly over the cliff face. Investigating the issue of inhomogeneity of the spatial distribution is of primary importance, because any spatial trend in the distribution might introduce a systematic bias affecting the scales and types of patterns: a phenomenon known as "virtual aggregation" (see e.g. Wiegand and Moloney, 2004).

In this view, a CSR model is fitted to both types of events (small or large). We analysed the spatial point process residuals of "cumulative raw" type, i.e. the differences between the fitted and the observed values, using the "lurking variable plot" (see further details in Baddeley et al., 2008 and references therein). The interest of this plot is that any systematic pattern (spatial trend) is indicated by a departure of the cumulative raw residuals outside the two-standard-deviation (a) Small

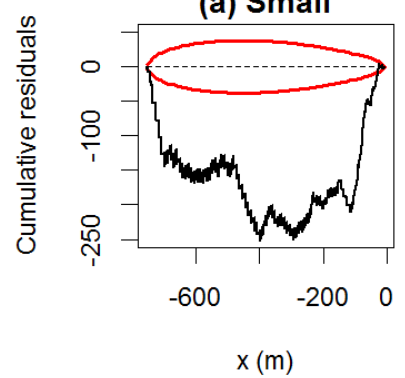

(c) Small

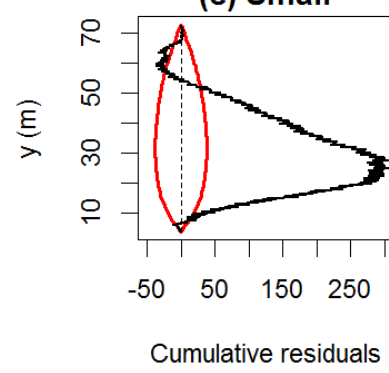

(b) Large

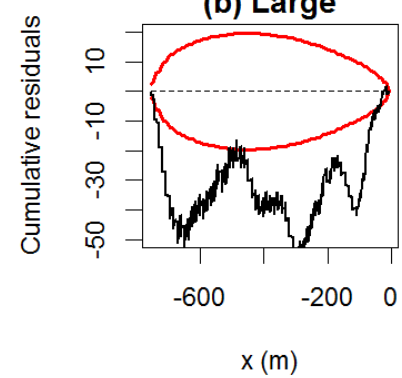

(d) Large

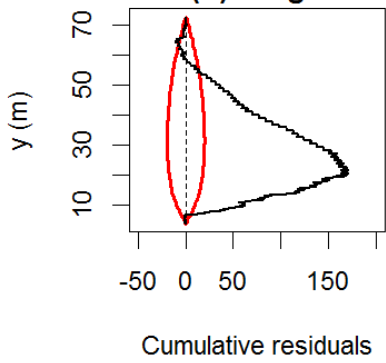

Figure 5. Lurking variable plots for the winter 2008 displaying the point process residuals (cumulative raw) under the assumption of complete spatial randomness against the $x$ coordinate (alongshore distance) and the $y$ coordinate (cliff elevation relative to NGF69 datum) for small erosion scars (a and $\mathbf{c}$ ), and for large erosion scars (b and d). The empirical plot (solid lines) is shown together with the pointwise two-standard-deviation limits (red lines).

limits. Those limits were calculated from the exact formula for the asymptotic variance of the residuals under the asymptotic normal approximation (Baddeley et al., 2008).

Considering small erosion scars, Fig. 5a and c show lurking variable plots for the last epoch of measurement in winter 2008 considering the spatial covariates ( $x$ and $y$ coordinate). This pair of plots indicates that complete spatial randomness is grossly inadequate to model the spatial process associated with erosion scars' distribution, because the departures outside the two-standard-deviation limits (red-coloured lines) are significant over the whole range of $x$ and $y$ coordinates, and more particularly with a clear positive deviation around an elevation $y=15-20 \mathrm{~m}$. These tendencies were also observed for the two other epochs of measurement in winter 2006 and 2007 (see Supplement), but differed alongshore during summers (see below).

Considering the group of large erosion scars, Fig. 5b shows that the cumulative residuals are close to the boundaries of the significance envelope: there is a weak-tomoderate dependence of the alongshore coordinate on the spatial density. In the winter 2006, the residuals even lie within the two-standard-deviation limits. On the other hand, Fig. 5d shows that the spatial density strongly depends on the height on the cliff with a maximum deviation around 15$20 \mathrm{~m}$ elevation just as for small erosion scars. 
(a) Small

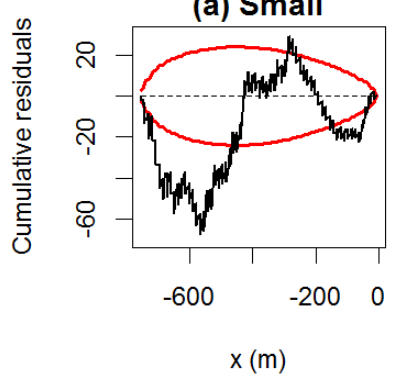

(c) Small

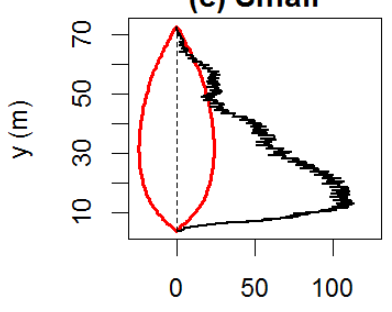

Cumulative residuals

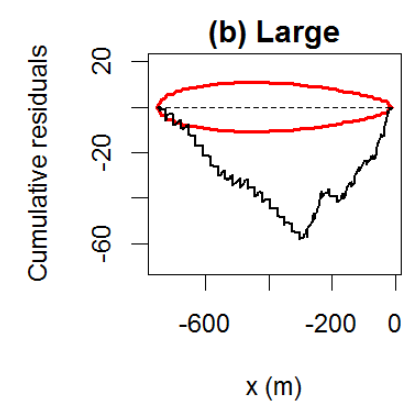

(d) Large

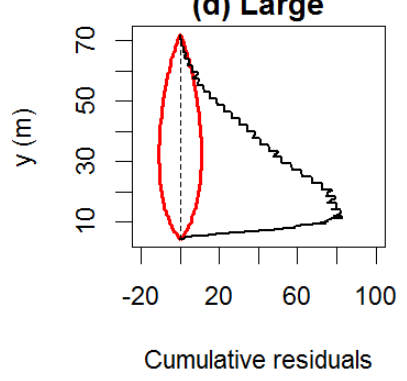

Figure 6. Lurking variable plots the summer 2006 displaying the point process residuals (cumulative raw) under the assumption of complete spatial randomness against the $x$ coordinate (alongshore distance) and the $y$ coordinate (cliff elevation relative to NGF69 datum) for small erosion scars (a and $\mathbf{c}$ ), and for large erosion scars (b and d). The empirical plot (solid lines) is shown together with the pointwise two-standard-deviation limits (red lines).

In the summer 2006, Fig. 6a and b show that the alongshore distance has a weak-to-moderate influence for both types of erosion scars, whereas Fig. $6 \mathrm{c}$ and d show that the dependence on the scar elevation remains strong. The latter finding was also verified in summer 2007 (see Supplement). On the contrary, the residuals appear to lie within the two-standard-deviation limits regarding both types of erosion scars. Considering the qualitative analysis in Fig. 4 (and over the entire cliff surface in Fig. 2), we get a deceptive impression of uniform distribution of small scars during summer 2006, but this apparent uniformity is not statistically significant and must have come up by chance.

To get a better insight into the spatial influence of spatial density, we conducted additional investigations by fitting a non-stationary Poisson process with an assumed spatial trend of the form

$\lambda(x, y) \propto \exp \left(c_{1} x+c_{2} y\right)$,

where $c_{1}$ and $c_{2}$ are the length scales governing the exponential decay.

Introducing exponential decay to explain scar density along the vertical direction ( $y$ coordinates) brings no fit improvement. The strong deviation at $y=15-20 \mathrm{~m}$ remains strongly significant. In the alongshore direction, however, the goodness-of-fit between the model and the observations is much improved. The residuals for both sizes of erosion scars

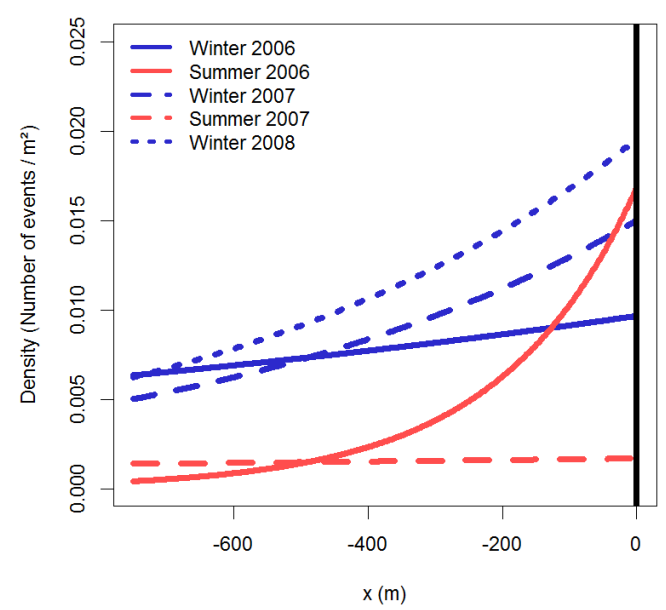

Figure 7. Evolution of the spatial density (number of events per unit area) alongshore ( $x$ coordinate) modelled by Eq. (6) for the large volumes considering the different measurement epochs. Note the position of the groyne at $x=0$.

now fall within the two-standard-deviation limits (see Supplement). Figure 7 provides the density alongshore for large volumes using Eq. (6) restricted to the alongshore direction ( $x$ coordinates). The magnitude of the decay parameter $c_{1}$ changes through time with a clear increase in winters. This tendency is less clear in summers (it is almost constant in summer 2007). Implications from a natural hazard assessment perspective are further discussed in Sect. 5 .

\subsection{Spatial dependence}

Section 4.1 has highlighted the spatial inhomogeneity for both types of erosion events (small and large). To explore the spatial dependence between points of the same type the inhomogeneous version of the $L$ function with Ripley's edge correction must be used similarly to the approach of Tonini and Abellan (2014). We assessed whether the scars follow an inhomogeneous Poisson process characterised by the same space-dependent intensity as the observed pattern: points locate themselves independently of each other, without mutual interaction, but with a spatial trend constrained by the spacedependent intensity. In this view, we relied on Monte-Carlo simulations by randomly generating points characterised by the assumed spatial behaviour. By comparing the empirical $L$ function with the ones generated, we could assess the significance of the deviations from the inhomogeneous Poisson process. On this basis, the spatial behaviour of the points can be classified (as described in Sect. 3.2).

Figure 8 shows this analysis with 99 random simulations using the data set of winter 2006. The upper and lower bounds of the simulated $L(r)-r$ correspond to the significance envelope. The deviations can then be assessed at a significance level of $2 \%$, which means that the hypothesis 

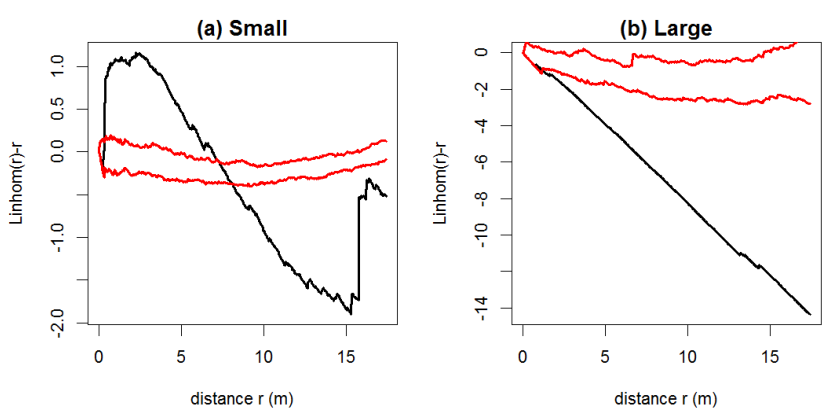

Figure 8. Empirical inhomogeneous $L$ function (minus the distance $r$ ) calculated for winter 2006 data set with Ripley's edge correction (black-coloured lines): for the small erosion scars, (a) $\left(10^{-3} \leq\right.$ volume $\left.\leq 10^{-2} \mathrm{~m}^{3}\right)$ and for the large scars (b) $\left(10^{-2} \leq\right.$ volume $\left.\leq 10^{1} \mathrm{~m}^{3}\right)$. The limits of the significance envelope (calculated through a Monte-Carlo procedure) at level of $2 \%$ are depicted by red curves.

for inhomogeneous Poisson process is rejected considering an error of $2 \%$.

Considering the data set of winter 2006, Fig. 8a shows that small events significantly deviate from the theoretical spatial behaviour: they tend to cluster in region of radii up to $7 \mathrm{~m}$ somehow attracting each other. Beyond this critical distance, they tend to repulse each other. Interestingly, this clustering/repulsion spatial pattern is similar whatever the epoch of measurement albeit with different aggregation thresholds: $9.00 \mathrm{~m}$ (summer 2006), $10.50 \mathrm{~m}$ (winter 2007), $5.50 \mathrm{~m}$ (summer 2007) and $10.75 \mathrm{~m}$ (winter 2008).

Regarding large events, they appear to follow the inhomogeneous Poisson process up to $\sim 1 \mathrm{~m}$ (empirical $L$ function remains within the significance envelope). This means that the clusters of large events observed in Fig. 4 cannot be considered significant and may have occurred by chance. Above $1 \mathrm{~m}$, Fig. 8b shows that larger events significantly deviate from the theoretical regular spatial behaviour. Below $1 \mathrm{~m}$, the influence of the geometry of the scars is expected to play a role (assumption for point abstraction does not hold). This propensity could not be analysed for summer epochs due to the dearth of large events. Considering winter 2007 and 2008, this threshold respectively reaches $\sim 5.0$ and $2.5 \mathrm{~m}$. Implications from a natural hazard assessment perspective are further discussed in Sect. 5.

\subsection{Temporal dependence}

After considering the distribution during single epochs, let us now address the question of precursory events prior to major rockfalls. Regarding this issue, Rosser et al. (2007) have analysed, during several months, the spatio-temporal distribution of rockfalls at the coast of the North York Moors National Park, UK: they have shown that smaller rockfalls tend to accumulate prior to large failures.
To investigate this, we relied on the multivariate form of the second order statistics (Eq. 5) so that points were assigned marks corresponding the epoch of measurement (e.g. "winter 2007"). To study the dependence between these marked points, we used the approach of "population independence" (e.g. Goreaud and Pélissier, 2003) by assuming that events of two different epochs are the results of two distinct spatial processes. Under the hypothesis of independence, the absence of interaction between the two types of points corresponds to an absence of interaction between the two populations. This means that point locations of a given epoch are independent of point location at a later epoch.

Test of independence relies on the simulation of the theoretical behaviour of "independent population". This is more complex than testing for CSR, because the structures of the different patterns (associated to each epoch of measurement) needs be preserved but the dependence between them needs be broken (Wiegand and Moloney, 2004). In practice, this can be achieved by keeping the patterns of both epochs unchanged, but their relative position is randomised at each Monte Carlo simulation (Lotwick and Silverman, 1982). This is achieved by randomising shifts of the spatial pattern of one population (for instance Winter 2007) relative to the other one (for instance Summer 2007).

The analysis was conducted for the consecutive epochs of measurement by distinguishing the type of events (small or large). The significance bounds were generated using 99 Monte-Carlo-based random shifts. The shift displacement vector was uniformly distributed in a rectangular window of a $5 \times 5 \mathrm{~m}$. Different window sizes were tested and their influence did not affect the conclusions (see Supplement). The non- rectangular shape of the cliff boundaries (see Fig. 1b) prevented us from using the toroidal shift proposed by Lotwick and Silverman (1982).

A first run was conducted considering only small erosion scars for each subsequent epochs. The analysis of Fig. 9 shows that the hypothesis of "population independence" holds true for the whole period of measurement. A second analysis was conducted only considering the large erosion scars. The analysis was restricted to epochs of measurement in winter, because there are too few large events in summer. Figure $10 \mathrm{c}$ and $\mathrm{d}$ show that there is a form of attraction between the events at small spatial scales $(<\sim 0.5 \mathrm{~m})$, meaning that large erosion scars tend to occur in the regions of the cliff which have already been "disturbed" and experienced erosion events during previous winter periods. The statistical significance of this finding remains however, moderate. A possible explanation may be linked to the coarse sixmonthly temporal resolution of our surveys, which may inhibit a stronger significance. Implications from a natural hazard assessment perspective are further discussed in Sect. 5. 
(a) Summer vs Winter 06

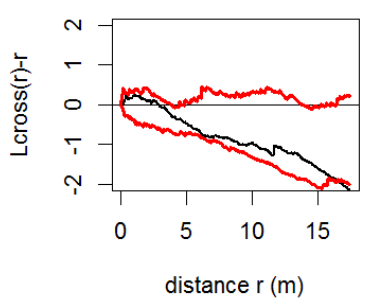

(c) Summer 07 vs Winter 07
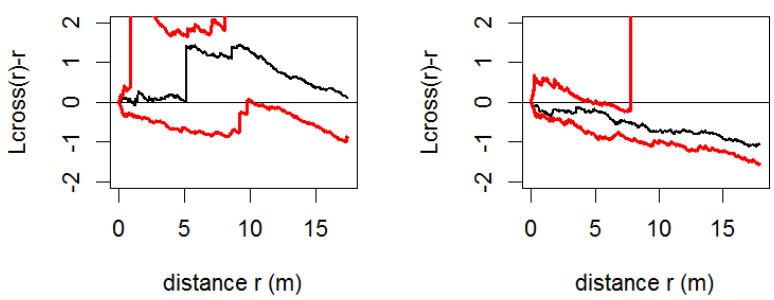

Figure 9. Cross-type $L$ functions computed between subsequent epochs of measurement (black-coloured lines) considering the small erosion scars. The limits of significance envelope at level of $2 \%$ associated to "population independence" hypothesis are depicted by red curves. (a) Winter 06 vs Winter 07

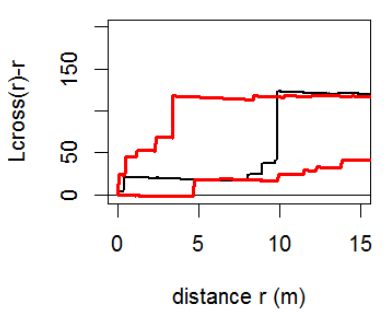

(c) Winter 06 vs Winter 07

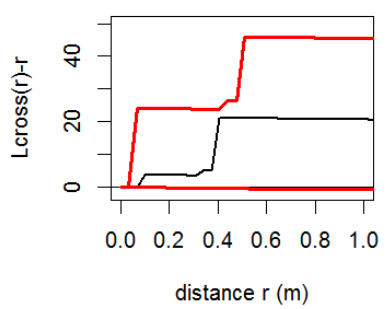

(b) Winter 07 vs Winter 08

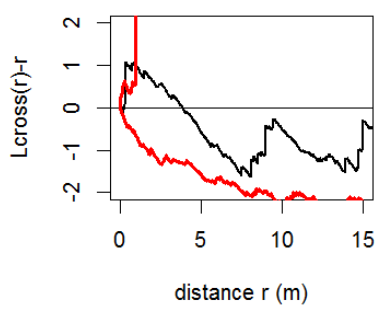

(d) Winter 07 vs Winter 08

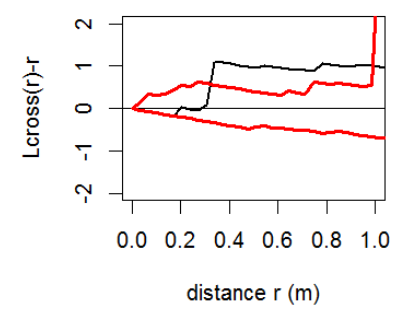

Figure 10. Cross-type $L$ functions computed between subsequent epochs of measurement in winter (black-coloured lines) considering the large erosion scars. (c) and (d) respectively correspond to a zoom on the distance range from 0 to $1 \mathrm{~m}$ of (a) and (b). The limits of significance envelope at level of $2 \%$ associated to the "population independence" hypothesis are depicted by red curves.

\section{Discussion}

The Mesnil-Val scar inventory was used in the past for natural hazards assessment purposes (see Dewez et al., 2007, 2013; Rohmer and Dewez, 2013). This study has focused on the small-to-moderate events with volumes smaller than $10 \mathrm{~m}^{3}$. Those events are the most frequent rockfall events and bear on the lower-end of the power-law-type frequencymagnitude relationship: they serve to infer the occurrence of larger sea-cliff instabilities and set cliff retreat estimates (Dewez et al., 2013; Rohmer and Dewez, 2013), hence the specific focus given to them here.

Not surprisingly, the analysis described in Sect. 4.1 confirms that the rockfall activity is heterogeneous in space. The histogram of the vertical distribution of the events (Fig. 1d) already suggested the dependency on the cliff elevation with a remarkable activity at $15-20 \mathrm{~m}$, but here the statistical significance was demonstrated. The peak activity is not due to chance. Two main physical mechanisms can be invoked to explain it.

The first cause can be related to sea assaults. Figure 11 shows an example of a wave breaking on the cliff face during the spring equinox tide on 20 March 2007 at 12:15. The photo was shot very near the high-tide maximum on a grim stormy day, with a tide coefficient of 116 (indicating high tide amplitude, to be compared to a maximum of 120 for the highest theoretically possible tide). Both static hydrographic sea-level characteristics from SHOM (2012) and the elevation reached by the dynamic effects of a breaking wave are reported on Fig. 11. Depending on wave dynamics (amplitude, frequency contents, etc.), wave run-up heights are very likely to reach elevations of 15 to $20 \mathrm{~m}$ (as shown by simulation-based studies like the ones by Carbone et al., 2013). With this example, one can easily understand why erosion scars, triggered by sea assault can occur as high as 15-20 m, even though the highest astronomical tide (HAT) only reaches $5.79 \mathrm{~m}$ (expressed in NGF69).

A second causative mechanism, possibly tangled with the effect of breaking waves, can be related to the presence of mechanical discontinuities: the Lewes Marl (see location of the geological marker unit in Fig. 11) and harder nodular chalk beds called hardgrounds (Mortimore et al., 2001). These mechanical contacts between rocks of dissimilar properties stop or deflect fracture propagation depending on properties contrasts (see e.g. He and Hutchinson, 1989). As it turns out on this cliff section, hardgrounds only occur in the lower section of the cliff below an elevation of $30 \mathrm{~m}$ and the Lewes Marl depositional geometry undulates between 15 and $20 \mathrm{~m}$ of elevation.

Vertically, erosion scars thus belong to two domains. At low elevation, a domain assaulted by waves at pretty much every high tide but with energy modulated by hydrodynamic processes of which a sharp lithological boundary appears to limit upward scar propagation. The second domain is above this threshold at $15-20 \mathrm{~m}$, where both projected sea-water 


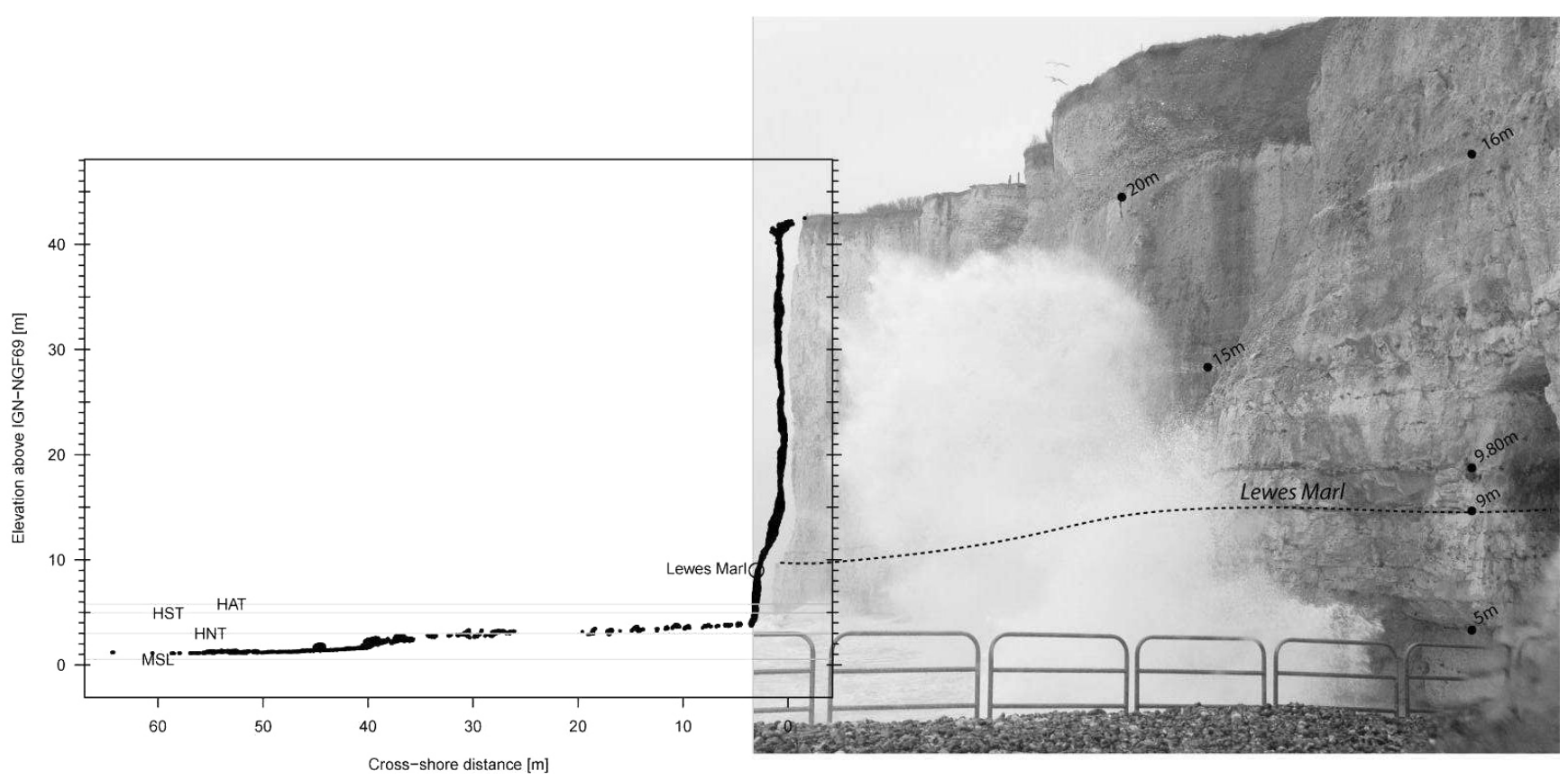

Figure 11. View of a sea wave breaking on the Mesnil-Val chalk cliff (looking north towards Le Tréport harbour) during high tide, photo T. Dewez, 20 March 2007. The left panel depicts laser-scanner-derived cross section of the cliff at the same place with indications of highest astronomical tide level (HAT), high spring tide level (HST), high neap tide level (HNT), and mean sea level (MSL), along with the Lewes Marl geological marker unit.

has little energy to detach small blocks and mechanical lithological discontinuities are more pervasive. Only continental processes affect the rock face and act evenly on the remainder of the cliff. This interpretation is supported by the observation that the spatial density appears to be constant towards the cliff top. Residuals in Figs. 5 and 6 all remain within the significance envelope.

Laterally now, the alongshore rockfall activity is also clearly variable. It is strongly influenced by the man-made, concrete groyne originally designed to retain a gravel beach of in front of Mesnil-Val dry valley (Fig. 1a). Rockfall activity is increased, mostly in winters and for large events, close to this shore-perpendicular structure. The engineering works are known to change local wave regime through wave refraction patterns, wave breaking and surf-zone circulation, producing rip currents close to the structures (Nordstrom, 2013). Changes in local hydrodynamic conditions result in accretion at the gravel beach of Mesnil-Val and pebble depletion on the downdrift side at the location of the cliff. The rockfall density relationship clearly follows an exponential shape controlled by parameter $c_{1}$ (Eq. 6), but relating this decay parameter to the grain characteristics, hydrodynamics conditions and groyne length-scale will require further investigations (e.g. based on studies similar to Mitchell and Pope, 2004). Our finding currently stops at establishing that rockfall hazard is promoted by the groyne and observing that the first $300 \mathrm{~m}$ of the cliff (twice the groyne length), has in particular recessed in the last 15 years (see Dewez et al., 2013). We will not venture in suggesting magnitudes of alongshore groyne effect.

Beyond the geographical distribution of scars, Sect. 4.2 highlighted that small events tended to cluster in 5 to $10 \mathrm{~m}$-radius regions, whereas the large ones tended to disperse. From a spatial distribution perspective, both behaviours cannot be considered equivalent. This distinction suggests that erosion processes and triggering factors differ between small and large scars. This implies that calibrating the power-law-type frequency-magnitude relationship whatever the rockfall volumes may perhaps not be appropriate throughout the volume range. This difference in dynamics suggests the existence of a minimum volume threshold above which the power-law is valid as discussed by Rohmer and Dewez (2013). This current study supports this intuition. Interestingly, Royan et al. (2014) also highlighted two dynamics depending on the volume of the rockfalls in a mountainous context. To make physical sense, the minimum volume threshold of power-law should be carefully evaluated in probabilistic rock fall hazard assessments.

Regarding the local neighbourhood of ruptures, the point pattern of each measurement epoch can be viewed as a ca. 6-month-long exposure snapshots of rockfalls. Section 4.2 showed a form of dispersion within the spatial patterns of large rockfalls. Much in the same way as with ecological species, this spatial dependency may indicate competition for space (e.g. Wiegand and Moloney, 2004 and references therein). First, the competition may be related to a geometri- 
cal argument: $\sim 90 \%$ of the large erosion scars can be embedded in a $2.85 \times 2.50 \mathrm{~m}$ rectangular bounding-box. New scars need to occur outside of this footprint extent, and hence centroids are necessarily scattered. This alludes to a notion of rock face collapse readiness. Once a large collapse has occurred, the rock face is not ready to fail in the next 6-months epoch.

A second explanation may be related to the dynamics of the progressive failures once a region of the cliff has failed. Though triggers and predisposing factors may be different, the study of Stock et al. (2012) at Yosemite Valley (USA) is instructive: they showed that successive rock falls of a single sequence were adjacent to a previous failure. As failures progressively radiates across the cliff face (see Fig. 5 in Stock et al., 2012), scar centroids of the next rockfall scars tend to distance themselves, which results in an increasingly scattered point pattern. We acknowledge that estimating the chronology of subsequent rock fall sequences at Mesnil Val would require higher time resolutions to pin point spatiotemporal pattern of Stock et al. (2012). However, the analysis of Sect. 4.3 can be useful to constrain the reset time of the rock face (time needed for the rock face to be little influenced by the disturbances induced by subsequent failures). Figure 10 showed that there is a moderate temporal correlation between events of subsequent winters. Hence, a given cliff region, which has experienced failure, is only moderately likely to shed new rocks in the next winter. To some extent, this suggests that this cliff region has reached a state of quasi-equilibrium after one year or more.

Finally, Stock et al. (2012) highlighted the key role of the fracture networks in the spreading of the failure. Yet, extrapolating a possible relationship between a distance to a fracture and the occurrence of a failure to the Mesnil Val case is not obvious (Dewez et al., 2013). Our regular observations of chalk cliff rupture over the last 10 years have shown us that existing fractures do not always limit scars. Rather the contrary, we have observed many times that chalk ruptures propagated through the matrix often ignoring the existing faults and fractures, or only following them to some distance and continuing to rupture seemingly intact matrix further on. The mechanical behaviour of this material can be very complex, and in particular characterised by low material cohesion (e.g. Lawrence et al., 2013) and strong sensitivity to the chemical and physical nature of pore fluid (promoting matrix failure as compared to failure along pre-existing discontinuities). On the top of that, contrasts in rock materials' properties and the presence of joints/bedding surfaces should also play an important role, and more especially the presence of the Lewes Marl layer, which appears to influence the vertical failure spreading as previously discussed.

\section{Conclusions}

In this article, we advocated that exploratory tools of spatial point process theory could be used as a tool to investigate some questions related to the spatial distribution of erosion scars over a coastal cliff face. Using an inventory of several thousands of erosion scars collated via repeated TLS surveys at the chalk coastal cliff of Mesnil-Val (France) for a period of 2.5 years, we quantitatively showed that: (1) the density of erosion scars depends on the locations over the cliff face this confirms that the erosion processes do not act similarly over space; (2) small erosion scars $\left[10^{-3}\right.$ to $\left.10^{-2} \mathrm{~m}^{3}\right]$ tend to aggregate in clusters of 5 to $10 \mathrm{~m}$ in radius. Beyond this threshold, erosion scars tend to disperse; (3) the spatial pattern of large erosion scars $\left[10^{-2}\right.$ to $\left.10^{1} \mathrm{~m}^{3}\right]$ tend to be regular above a radius of 1 to $5 \mathrm{~m}$, indicating a form of competition for space; (4) large events occur in regions having already experienced erosion events during the previous winter periods, is statistically significant at a moderate level; (5) this form of temporal dependence does not emerge for small events in this inventory. Further work should be conducted using data sets with higher temporal resolutions to verify this dependence.

Spatial point process statistics is a class of exploratory data analysis techniques helping supporting qualitative geomorphological observations and testing their significance. They clearly are only a first step to explore the physical processes underlying coastal cliff erosion. We have formulated a few hypotheses to explain the statistical significance of tendencies outlined by the approach at Mesnil-Val (France). Future studies should account for more controlling factors and explanatory variables like rock mass properties in a similar manner as Le Cossec et al. (2011), fracture network (e.g. Duperret et al., 2004) or wave regime (and energy distribution) along the coastline and engineering works induced disturbances (e.g. Mitchell and Pope, 2004).

Investigations were conducted over a range of erosion volumes for which the point abstraction assumption remains valid. Our understanding of the radius for aggregation (or repulsion) outlined by the present analysis is expected to be improved by using statistical tools accounting for the shape of the objects investigated (Wiegand et al., 2006). A second line of improvement should rely on integrating both time and space following, for instance, the methods applied for wildfires by Hering et al. (2009).

\section{The Supplement related to this article is available online at doi:10.5194/nhess-15-349-2015-supplement.}


Acknowledgements. This work was supported by BRGM-funded "DEV-ESCARP" project. We thank D. Idier (BRGM) for useful discussion on wave actions. We thank the two anonymous reviewers for their comments, which led to improvements to this article.

Edited by: F. Guzzetti

Reviewed by: two anonymous referees

\section{References}

Baddeley, A. and Turner, R.: spatstat: An R Package for Analyzing Spatial Point Patterns, J. Stat. Software, 12, 2005.

Baddeley, A., Moller, J., and Waagepetersen, R.: Non- and semiparametric estimation of interaction in inhomogeneous point patterns, Statistica Neerlandica, 54, 329-350, 2000.

Baddeley, A., Møller, J., and Pakes, A. G.: Properties of residuals for spatial point processes, Ann. I. Stat. Math., 60, 627-649, 2008.

Besag, J. E.: Contribution to the discussion of Dr. Ripley’s paper, J. Roy. Stat. Soc. B, 39, 193-195, 1977.

Bird, F.: Coastal Geomorphology, an Introduction, Wiley, Chicester, UK, 322 pp., 2000.

Brossard, J. and Duperret, A.: Coastal chalk cliff erosion: experimental investigation on the role of marine factors, in: Coastal Chalk Cliff Instability Engineering Geology, edited by: Mortimore, R. N. and Duperret, A., Special Publications, London, UK, 139-148, 2004

Brunetti, M. T., Guzzetti, F., and Rossi, M.: Probability distributions of landslide volumes, Nonlin. Processes Geophys., 16, 179-188, doi:10.5194/npg-16-179-2009, 2009.

Carbone, F., Dutykh, D., Dudley, J. M., and Dias, F.: Extreme wave runup on a vertical cliff, Geophys. Res. Lett., 40, 3138-3143, 2013.

Costa, S., Delahaye, D., Freire-Diaz, S., Di Nocera, L., Davidson, R., and Plessis, E.: Quantification of the Normandy and Picardy chalk cliff retrat by photogrammetric analysis, in: Coastal Chalk Cliff Instability Engineering Geology, edited by: Mortimore, R. N. and Duperret, A., Special Publications, London, UK, 139148, 2004.

Dewez, T., Rohmer, J., and Closset, L.: Laser survey and mechanical modeling of chalky sea cliff collapse in Normandy, France, in: Proceedings of Landslides and Climate Change, Challenges and Solutions (Isle of Wight, England), edited by: McInnes, R., Jakeways, J., Fairbanks, H., and Mathie, E., Taylor \& Francis, London, UK, 281-288, 2007.

Dewez, T., Rohmer, J., Regard V., and Cnudde, C.: Probabilistic coastal cliff collapse hazard from repeated terrestrial laser surveys: case study from Mesnil Val (Normandy, northern France), in: Proceedings 12th International Coastal Symposium (Plymouth, England), edited by: Conley, D. C., Masselink, G., Russell, P. E., and O'Hare, T. J., J. Coastal Res., Special Issue No. 65, 702-707, 2013.

Diggle, P. J.: Statistical Analysis of Spatial Point Patterns, 2nd edition, Arnold, London, UK, 159 pp., 2003.

Dong, P. and Guzzetti, F.: Frequency-size statistics of coastal softcliff erosion, J. Waterw. Port C. Div., 131, 37-42, 2005.

Duperret, A., Genter, A., Martinez, A., and Mortimore, R.: Coastal chalk cliff instability in NW France: role of lithology, fracture pattern and rainfall, in: Coastal chalk cliff instability, edited by: Mortimore, R. N. and Duperret, A., Engineering Geology Special publications, Geological Society, London, UK, 20, 33-55, 2004.

Emery, K. O. and Kuhn, G. G.: Sea cliffs: their processes, profiles, and classification, Bull. Geol. Soc. Am., 93, 644-654, 1982.

Goreaud, F. and Pélissier, R.: Avoiding misinterpretation of biotic interactions with the intertype K12-function: population independence vs. random labelling hypotheses, J. Veg. Sci., 14, 681692, 2003.

Guzzetti, F., Mondini, A. C., Cardinali, M., Fiorucci, F., Santangelo, M., and Chang, K.-T.: Landslide inventory maps: New tools for an old problem, Earth-Sci. Rev., 112, 42-66, 2012.

Haase, P.: Spatial pattern analysis in ecology based on Ripley's K function: Introduction and methods of edge correction, J. Veg. Sci., 6, 575-582, 1995.

He, M. Y. and Hutchinson, J. W.: Crack deflection at an interface between dissimilar elastic materials, Int. J. Solids Struct., 25, 1053 1067, 1989.

Hering, A., Bell, C., and Genton, M.: Modelling spatio-temporal wildfire ignition point patterns, Environ. Ecol. Stat., 16, 225250, 2009.

Lawrence, J. A., Mortimore, R. N., Stone, K. J., and Busby, J. P.: Sea saltwater weakening of chalk and the impact on cliff instability, Geomorphology, 191, 14-22, 2013.

Le Cossec, J., Duperret, A., Vendeville, B. C., and Taibi, S.: Numerical and physical modelling of coastal cliff retreat processes between La Hève and Antifer capes, Normandy (NW France), Tectonophysics, 510, 104-123, 2011.

Lim, M., Rosser, N. J., Allison, R. J., and Petley, D. N.: Erosional processes in the hard rock coastal cliffs at Staithes, North Yorkshire, Geomorphology, 114, 12-21, 2010.

Lotwick, H. W. and Silverman, B. W.: Methods for analysing spatial processes of several types of points, J. Roy. Stat. Soc. B, 44, 403413, 1982.

Marques, F. M. S. F.: Magnitude-frequency of sea cliff instabilities, Nat. Hazards Earth Syst. Sci., 8, 1161-1171, doi:10.5194/nhess8-1161-2008, 2008.

Mitchell, S. B. and Pope, D. J.: Prediction of nearshore wave energy distribution by analysis of numerical wave model output, East Sussex coastline, UK, Geological Society, Engineering Geology Special Publications, London, UK, 20, 99-107, 2004.

Mortimore, R. N., Wood, C. J., and Gallois, R. W.: British Upper Cretaceous Stratigraphy, Geological Conservation Review Series 23, Joint Nature Conservation Committee: Peterborough, UK, 558 pp., 2001.

Naylor, L. A., Stephenson, W. J., and Trenhaile, A. S.: Rock coast geomorphology: Recent advances and future research directions, Geomorphology, 114, 3-11, 2010.

Nordstrom, K. F.: Living with shore protection structures: A review, Estuarine, Estuar. Coast. Shelf S., 150, 11-23, doi:10.1016/j.ecss.2013.11.003, 2013.

R Development Core Team: A Language and Environment for Statistical Computing. Vienna, Austria : the R Foundation for Statistical Computing, available at: http://www.R-project.org/, last access: 19 December, 2014.

Regard, V., Dewez, T., Bourles, D. L., Anderson, H., Duperret, A., Costa, S., Leanni, L., Lasseur, E., Pedoja, K., and Maillet, G. M.: Late Holocene sea-cliff retreat recorded by $10 \mathrm{Be}$ profiles across a 
coastal platform: Theory and example from the English Channel, Quat. Geochronol., 11, 87-97, 2012.

Ripley, B. D.: The second-order analysis of stationary point processes, J. Appl. Probab., 13, 255-266, 1976.

Ripley, B. D.: Spatial data analysis, Encycl. Statist. Sci., 8, 570573, 1988.

Royán, M. J., Abellán, A., Jaboyedoff, M., Vilaplana, J. M., and Calvet, J.: Spatio-temporal analysis of rockfall pre-failure deformation using Terrestrial LiDAR, Landslides, 1-13, 2013.

Rohmer, J. and Dewez, T.: On the deviation of extreme sea-cliff instabilities from the power-law frequency-volume distribution: practical implications for coastal management, in: Proceedings 12th International Coastal Symposium (Plymouth, England), edited by: Conley, D. C., Masselink, G., Russell, P. E., and O'Hare, T. J., J. Coastal Res., Special Issue No. 65, 1698-1703, 2013.

Rosser, N. J., Petley, D. N., Lim, M., Dunning, S. A., and Allison, R. J.: Terrestrial laser scanning for monitoring the process of hard rock coastal cliff erosion, Q. J. Eng. Geol. Hydrogeol., 38, 363375, 2005.

Rosser, N., Lim, M., Petley, D., Dunning, S., and Allison, R.: Patterns of precursory rockfall prior to slope failure, J. Geophys. Res. 112, F04014, doi:10.1029/2006JF000642, 2007.

Royán, M. J., Abellán, A., Jaboyedoff, M., Vilaplana, J. M., and Calvet, J.: Spatio-temporal analysis of rockfall pre-failure deformation using Terrestrial LiDAR, Landslides, 11, 697-709, 2014.

Schoenberg, F. P.: Multi-dimensional residual analysis of point process models for earthquake occurrences, J. Am. Stat. Assoc., 98, 789-795, 2003.

SHOM: Référence altimétrique Zone Manche Est, available at: http://www.shom.fr/fileadmin/SHOM/PDF/04-Activites/ RAM2012.pdf(last access: 9 December 2013), 2012.
Stock, G. M., Martel, S. J., Collins, B. D., and Harp, E. L.: Progressive failure of sheeted rock slopes: the 2009-2010 Rhombus Wall rock falls in Yosemite Valley, California, USA, Earth Surf. Proc. Land., 37, 546-561, 2012.

Sunamura, T.: Geomorphology of Rocky Coasts, Wiley, New York, 302 pp., 1992.

Tonini, M. and Abellán, A.: Rockfall detection from terrestrial LiDAR point clouds: A clustering approach using R, J. Spat. Inf. Sci., 8, 95-110, 2014.

Tonini, M., Pedrazzini, A., Penna, I., and Jaboyedoff, M.: Spatial pattern of landslides in Swiss Rhone Valley, Nat. Hazards, 73, 97-110, 2014.

Wiegand, T. and Moloney, K. A.: Rings, circles and null-models for point pattern analysis in ecology, Oikos, 104, 209-229, 2004.

Wiegand, T., Kissling, W. D., Cipriotti, P. A., and Aguiar, M. R.: Extending point pattern analysis to objects of finite size and irregular shape, J. Ecol., 94, 825-837, 2006.

Wolters, G. and Müller, G.: Effect of cliff shape on internal stresses and rock slope stability, J. Coastal Res., 24, 43-50, 2008.

Young, A. P., Guza, R. T., O'Reilly, W. C., Flick, R. E., and Gutierrez, R.: Short-term retreat statistics of a slowly eroding coastal cliff, Nat. Hazards Earth Syst. Sci., 11, 205-217, doi:10.5194/nhess-11-205-2011, 2011. 